\title{
Severe anterior uveitis associated with idiopathic dacryoadenitis in diabetes mellitus patient
}

This article was published in the following Dove Press journal:

Clinical Ophthalmology

I3 May 201 I

Number of times this article has been viewed

\section{Yasuhiro Takahashi' \\ Hirohiko Kakizaki' \\ Akihiro Ichinose ${ }^{2}$ \\ Masayoshi Iwaki'}

'Department of Ophthalmology, Aichi Medical University, Nagakute, Aichi, Japan; ${ }^{2}$ Department of Plastic Surgery, Kobe University, Kobe, Hyogo, Japan
Correspondence: Hirohiko Kakizaki Department of Ophthalmology, Aichi Medical University, Nagakute, Aichi 480-I 195, Japan

$\mathrm{Tel}+8|56|-62-33||$

Fax +8I 56I-63-7255

Email cosme@dI.dion.ne.jp
Abstract: A 38-year-old woman with diabetes mellitus complained of acute visual loss in the left eye (20/200) and swollen left upper eyelid. Slit lamp examination of the left eye revealed ciliary injection, posterior synechia iritis, numerous inflammatory cells, and fibrin exudates in the anterior chamber. T1-weighted enhanced magnetic resonance imaging demonstrated left lacrimal gland enhancement with inflammatory spread to the left anterior ocular segment. Blood examination showed increased blood sugar but the other components were within normal limits. The patient was treated with steroid pulse therapy (methylprednisolone $1 \mathrm{~g} /$ day $\times 3$ days) under a blood sugar control regimen in consultation with an endocrinologist, after which additional peribulbar injection of triamcinolone acetonide $(40 \mathrm{mg})$ was performed. Resolution of the anterior uveitis and the dacryoadenitis was obtained after 2 months and there was no recurrence 1 year after the therapy. This is a rare case of severe anterior uveitis caused by idiopathic dacryoadenitis in a patient with diabetes mellitus.

Keywords: anterior uveitis, idiopathic dacryoadenitis, diabetes mellitus, magnetic resonance imaging, steroid

\section{Introduction}

Anterior uveitis is an extremely rare complication of dacryoadenitis. Dacryoadenitis usually causes local symptoms such as swelling of the lacrimal gland and the upper eyelid, and temporal conjunctival injection. ${ }^{1}$ Only one case has been reported on anterior uveitis with mild inflammatory cells in the anterior chamber associated with lacrimal grand sarcoidosis. ${ }^{2}$

We report a case of severe anterior uveitis caused by idiopathic dacryoadenitis in a patient with diabetes mellitus.

\section{Case report}

A 38-year-old woman with diabetes mellitus complained of bilateral palpable lacrimal gland enlargement. She did not exhibit eyelid edema or tenderness at the time. Her visual acuity was 20/20 OU and intraocular pressure was $19 \mathrm{mmHg}$ OU. Hertel exophthalmometry revealed $17 \mathrm{~mm}$ bilaterally. The ocular motility was normal and slit lamp examination did not demonstrate conjunctival injection, and inflammation in the anterior chamber and the vitreous cavity in both eyes.

Two weeks after the initial examination, the patient noticed acute visual loss and conjunctival injection in the left eye, and left eyelid swelling. Her left visual acuity declined to 20/200 OS, and left intraocular pressure increased to $28 \mathrm{mmHg}$. Hertel exophthalmometry indicated $20 \mathrm{~mm}$ OS, ie, $3 \mathrm{~mm}$ more proptotic than the measurement 
taken 2 weeks before. Movement of the left lateral rectus was restricted. Swelling and tenderness occurred in the left upper eyelid (Figure 1A). Slit lamp examination of the left eye disclosed ciliary injection, posterior synechia iritis, numerous inflammatory cells, and fibrin exudates in the anterior chamber (Figure 1B), although no inflammatory sign was shown in the vitreous cavity. T1-weighted enhanced magnetic resonance imaging (MRI) illustrated enhancement of the left lacrimal gland and the anterior segment of the left globe (Figure 1C). The fasting blood sugar level was $201 \mathrm{mg} / \mathrm{dL}$ at the time, but blood tests for angiotensin-converting enzyme, rheumatoid factors, antinuclear antibodies, thyroid-related autoantibodies, antineutrophil cytoplasmic antibodies, antiSjögren syndrome A and B antibodies, soluble interleukin-2 receptor, and virus-associated immunoglobulins were all within normal limits or negative. The chest radiograph did not show hilar lymphadenopathies. The needle reaction was negative on physical examination. According to the findings, we diagnosed it as an idiopathic orbital inflammatory syndrome (lacrimal type). ${ }^{3}$ In addition, we judged that the lacrimal gland inflammation caused the anterior uveitis.

After consulting an endocrinologist, we treated the patient immediately with steroid pulse therapy (methylprednisolone, $1 \mathrm{~g} /$ day) for 3 successive days without oral steroids thereafter. Simultaneously, eye drops (dexamethasone, phenylephrine hydrochloride, and tropicamide) were administered 4 times a day. Fasting blood sugar was examined 3 times a day during the steroid pulse therapy. A hypoglycemic agent was administered, and insulin injection was transiently used for temporary increase of blood sugar (when $>250 \mathrm{mg} / \mathrm{dL}$ ). Since slight eyelid swelling and uveitis remained 2 weeks after the second examination, triamcinolone acetonide $(40 \mathrm{mg}$ ) was then injected into the left orbit via the supralateral part of the subtenon space. Two months after the second examination, her visual acuity improved to 20/20 OS with complete

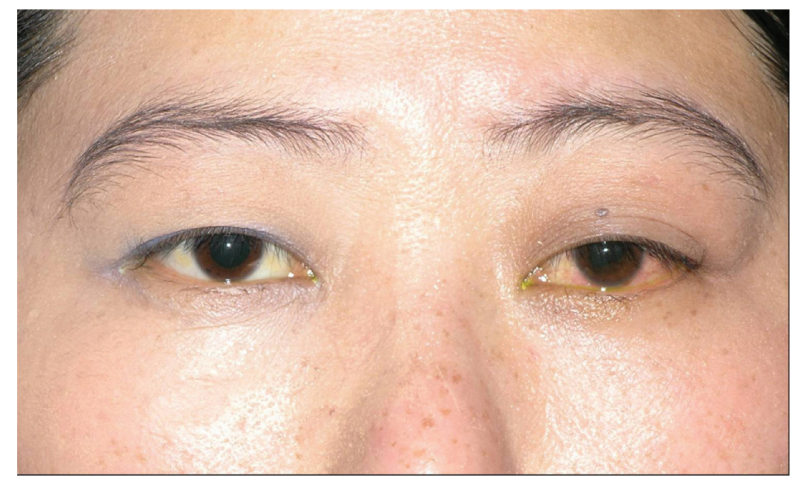

Figure IA Patient photograph. Swollen left upper eyelid with redness.

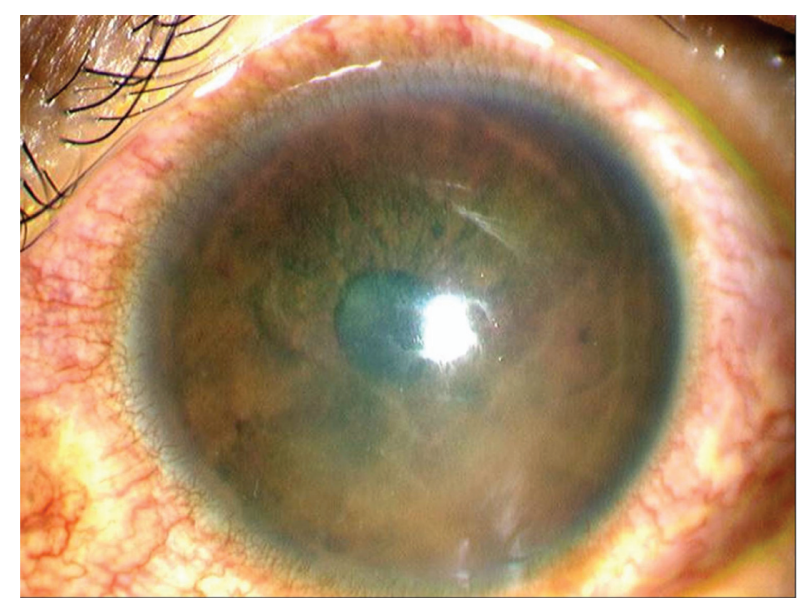

Figure IB Slit lamp examination of the left eye. Ciliary injection, posterior synechia iritis, and fibrin tissues in the anterior chamber are shown.

resolution of the anterior uveitis and dacryoadenitis, without serious systemic side effects. Left intraocular pressure decreased to $19 \mathrm{mmHg}$ during the treatment, and steroidinduced glaucoma did not occur. There was no recurrence 1 year after the therapy.

\section{Discussion}

The patient reported herein showed severe anterior uveitis caused by dacryoadenitis. This is an extremely rare entity, and only one sarcoidosis case with simultaneous anterior uveitis and dacryoadenitis has been reported so far. ${ }^{2}$ Sarcoidosis was excluded in our case on the results of the examinations, although biopsy was not performed. The severe anterior uveitis here was caused by the extension of simple dacryoadenitis without inflammatory disease background.

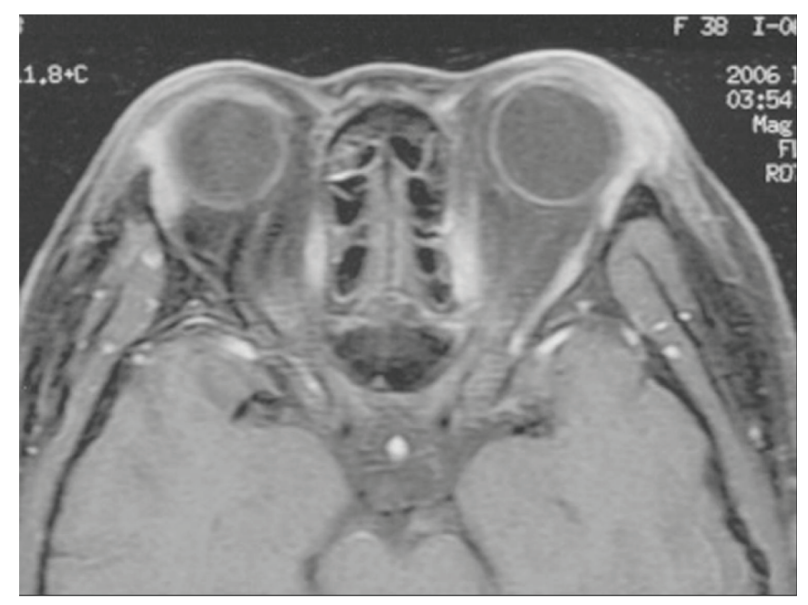

Figure IC TI-weighted enhanced magnetic resonance image. The spread of the lacrimal gland inflammation to the anterior segment of the left eye and the lateral rectus muscle is seen. 
Idiopathic dacryoadenitis, therefore, should be considered as a possible cause of an anterior uveitis.

MRI is a useful tool for detecting dacryoadenitis, and contrast enhancement is more helpful for understanding inflammatory expansion. As our patient presented with palpable lacrimal gland enlargement, proptosis, and eyelid swelling in addition to the anterior uveitis, we took the MRI. When a patient shows findings other than simple uveitis, MRI with contrast enhancement is an essential examination for diagnosing the condition.

Our patient had diabetes mellitus, wherein vascular permeability increases. ${ }^{3}$ Diabetes mellitus causes vascular barrier damage, resulting in plasma leakage and fluid retention in surrounding tissues. ${ }^{4}$ Diabetes mellitus may have aggravated the inflammation, causing a larger inflammatory expansion.

We performed a short-term steroid pulse therapy, which is an effective procedure for treating both orbital inflammation and anterior uveitis. ${ }^{5,6}$ Although oral steroid therapy is occasionally used for such patients, it is often ineffective with long-term administration, causing many side effects. ${ }^{1}$ However, steroid pulse therapy may also induce vital side effects, such as a lethal level blood sugar, to patients with diabetes mellitus. Therefore, blood sugar in our patient was closely monitored and properly controlled by an endocrinologist during the treatment. We additionally performed a triamcinolone acetonide injection, which may have contributed to avoid serious systemic side effects with complete resolution of the uveitis and dacryoadenitis. ${ }^{7}$

In conclusion, our patient with diabetes mellitus showed severe anterior uveitis caused by idiopathic dacryoadenitis, the diagnosis of which was aided by MRI. The treatment was successfully performed by the steroid pulse and local injection therapies with assistance of an endocrinologist.

\section{Disclosure}

The authors have no financial support and no financial interest related to this manuscript.

\section{References}

1. Yuen SJA, Rubin PAD. Idiopathic orbital inflammation: distribution, clinical features, and treatment outcome. Arch Ophthalmol. 2003;121: 491-499.

2. Nowinski T, Flanagan J, Ruchman M. Lacrimal gland enlargement in familial sarcoidosis. Ophthalmology. 1983;90:909-913.

3. Rootman J. Orbital inflammation disease: classification and new insights. In: Rootman J, editor. Orbital Disease: Present Status and Future Challenges. Boca Raton: Taylor \& Francis; 2005:1-14.

4. Yuan SY, Breslin JW, Perrin R, et al. Microvascular permeability in diabetes and insulin resistance. Microcirculation. 2007;14:363-373.

5. Kau HC, Kao SC, Peng CH, Hsu WM, Tsai CC. Methylprednisolone pulse therapy in patients with isolated superior oblique myositis. Eye. 2006;20:1106-1109.

6. Wakefield D, McCluskey P, Penny R. Intravenous pulse methylprednisolone therapy in severe inflammatory eye disease. Arch Ophthalmol. 1986; 104:847-851.

7. Leibovitch I, Prabhakaran VC, Davis G, Selva D. Intraorbital injection of triamcinolone acetonide in patients with idiopathic orbital inflammation. Arch Ophthalmol. 2007;125:1647-1651.
Clinical Ophthalmology

\section{Publish your work in this journal}

Clinical Ophthalmology is an international, peer-reviewed journal covering all subspecialties within ophthalmology. Key topics include: Optometry; Visual science; Pharmacology and drug therapy in eye diseases; Basic Sciences; Primary and Secondary eye care; Patient Safety and Quality of Care Improvements. This journal is indexed on

Submit your manuscript here: http://www.dovepress.com/clinical-ophthalmology-journal

\section{Dovepress}

PubMed Central and CAS, and is the official journal of The Society of Clinical Ophthalmology (SCO). The manuscript management system is completely online and includes a very quick and fair peer-review system, which is all easy to use. Visit http://www.dovepress.com/ testimonials.php to read real quotes from published authors. 